\title{
The Endonasal Endoscopic Management of Paranasal Sinuses Mucoceles
}

\author{
Sarah A. AlMansour ${ }^{1}$, Ali A. AlMomen ${ }^{2}$ \\ ${ }^{1}$ Otorhinolaryngology Head and Neck Surgery Resident, King Fahad Specialist Hospital, Dammam, KSA \\ ${ }^{2}$ Senior Consultant Rhinology and Skull Base Surgeon, King Fahad Specialist Hospital, Dammam, KSA \\ Email: Ali.Moumen@kfsh.med.sa
}

How to cite this paper: AlMansour, S.A. and AlMomen, A.A. (2021) The Endonasal Endoscopic Management of Paranasal Sinuses Mucoceles. International Journal of Otolaryngology and Head \& Neck Surgery, 10, 20-29.

https://doi.org/10.4236/ijohns.2021.101003

Received: October 23, 2020

Accepted: January 23, 2021

Published: January 26, 2021

Copyright $\odot 2021$ by author(s) and Scientific Research Publishing Inc. This work is licensed under the Creative Commons Attribution International License (CC BY 4.0).

http://creativecommons.org/licenses/by/4.0/

\begin{abstract}
Introduction: Paranasal sinuses mucoceles are benign, epithelial lined, mucus filled lesions, causing destruction of the adjacent sinus walls, and with further gradual extension to adjacent structures, serious morbidities and mortalities may occur. Objective: To emphasize on the efficacy of endonasal endoscopic marsupialization in the treatment of paranasal sinus mucoceles. Method: Retrospective descriptive study on paranasal sinus mucocele cases operated on endoscopically by the author (AAM), in the 10-year-period from to 2009-2019. Result: Total of 23 cases were included, 16 were males and 7 females, age ranging between 14 - 76 years, with a mean age of 45 years Location of mucoceles varied between: Frontal 7 cases (30\%), Fronto-ethmoidal 6 cases (26\%), Isolated Ethmoidal accounted for 3 cases (13\%), sphenoidal 4 cases (17\%), maxillary were 3 cases (13\%) all of the 23 cases underwent endonasal endoscopic complete marsupialization, none of them required combination with external approach in-spite of different locations and complications, with no recurrence in a mean follow up period of 2.4 years. Conclusion: Endonasal endoscopic approach is a safe, efficient approach in the treatment of most paranasal sinus mucocele case in their different presentations and locations.
\end{abstract}

\section{Keywords}

Mucocele, Paranasal Sinus, Chronic Rhinosinusitis, Endoscopic Sinus Surgery, Marsupialization

\section{Introduction}

Mucoceles are defined as benign, pseudocystic, slowly growing, expansile, locally destructive lesions. It is epithelial lined, filled with inspissated mucus, causing bony erosions or resorption \& displacement of the adjacent structures, when it 
gets infected, a mucopyocele is formed with a risk of orbital cellulitis, meningitis, and brain abscess.

As for the constitution it was first described as Hydatides by Langenbeck in 1818 who described the frontal sinus mucocele in details, Rollet was the one who suggested the term Mucocele in 1896. The first histological description was by Onodi in 1901.

In fact, in a study done by Lund and Milroy in 1991, it was found that the mucocele lining does show the histologic characteristics of respiratory mucosa [1].

Batsakis in 1980 has proposed that cystic degeneration of a seromucinous gland, thus constituting a retention cyst is a possible mechanism of mucocele formation [2]. There is no clinical or histological evidence from previous studies to support this proposition. In fact, retention cysts are commonest in the maxillary sinus where mucoceles are least likely to be found [3].

The more convincing theory of the formation is: sinus ostium obstruction leading to sinus inflammation and mucocele formation. Obstructive etiologies of the sinuses are many, including: Mass lesions, fibrosis, inflammation, osteoma, fibrous dysplasia, Paget's disease, malignancy, trauma, previous surgery.

Although paranasal sinuses mucoceles are considered benign lesions, they might carry a significant destructive effect to adjacent structures (e.g. intra-orbital or intracranial extensions and their possible consequences), there are two proposed theories explaining the expansile and destructive nature of these lesions.

The Pressure necrosis theory, in which, positive pressure exerted by mucus in an obstructed sinus causes necrosis of the underlying bone [4].

The other one is the inflammation theory, in which the activation of leukocytes and lymphocytes, leading to the production of (IL-1, IL-6), Activation of (PGE2, collagenase) leading to bone resorption \& remodeling and subsequent mucocele expansion [5].

The Frontal sinus Most commonly involved, followed by ethmoid, maxillary and sphenoid sinuses [6] [7] [8].

The reason of the propensity of the frontal sinus to be the most affected is that the frontal sinus is distinct from the normal pseudostratified ciliated columnar epithelium both histologically and pathologically, it tends to have a flatter more cuboidal epithelium with greater propensity for mucocele formation [9].

Based on the location and size of the mucocele, the clinical presentation may vary between: Pain, nasal congestion, facial swelling, headache, dental pain. Other possible location specific symptoms can be divided as ocular symptomatology that predominates the anterior ethmoid-frontal locations including: proptosis, periorbital pain, impaired ocular mobility, blurred/loss of vision, diplopia. Cheek and vestibule swelling is the most common presentation sign in maxillary mucoceles. Neurological signs: resulting from compression of cerebrum, cranial nerves, or optic nerve leading to Confusion, Meningitis, CSF leak, vision changes. Suspicious elements in the history might raise the indication towards sinus mu- 
cocele are: Facial trauma, surgery, allergic/inflammatory sinus disease.

Contrasted CT remains the gold standard mean in diagnosing these lesions. Typical mucocele contents have low density and do not enhance, as mucus becomes more inspissated, the density may increase. MRI can be added for soft tissue delineation and to detect the complications, and the intensity varies with the protein content and the degree of hydration

The differential diagnosis includes dermoid and epidermoid cysts, angiofibroma, neurofibromas, osseous fibromas, cholesterol granulomas, odontogenic cysts. All of these lesions may cause expansion similar to mucoceles in the sinus wall. The introduction of endoscopic management of paranasal sinuses mucoceles was by Kennedy in 1989. He described the endoscopic marsupialization, leaving the lining mucosa behind [10].

Endoscopic techniques have been presented to be secure and efficient alternatives for extra-nasal surgical treatment of paranasal sinus mucoceles [10] [11].

The use of Image Guidance by Navigation has become integrated into our endoscopic sinonasal approach for several purposes: providing accurate bony demarcation, making endoscopic approach more (safe), reducing complication rate, especially in complicated or advanced lesions [12].

The American Academy of Otolaryngology-Head and Neck Surgery (AAO-HNS) has published in 2005-based on the expert opinion-their agreement on the indications of image guidance in sinus surgery including: Revision FESS, distorted sinus anatomy of various etiologies, extensive polyposis, (frontal, posterior ethmoid or sphenoid sinuses pathology), disease involving critical structures, benign and malignant sinonasal neoplasms [13].

A good number of published case series and case reports has shown that endoscopic marsupialization has become the approach of choice in the majority of patients attaining a satisfactory clinical outcome and a lower rate of recurrence [14]-[20].

The risk factor of recurrence after marsupialization is thought to be: Surgery during acute infection, presence of multiple mucoceles, significant extension outside the sinus wall.

\section{Aim and Objectives}

To emphasize on the efficacy of endoscopic marsupialization in the treatment of paranasal sinus mucoceles.

In addition to enriching the literature with more evidence that contributes to the recognition of the endonasal endoscopic management as the first line in the treatment of variant extension degrees of paranasal sinuses mucoceles.

\section{Methods and Materials}

The study was a retrospective descriptive study of the adult patients operated on by a Single Surgeon Dr. AAM in both Inselspital hospital, University of Bern, Switzerland and King Fahad Specialist Hospital-Dammam, KFSH-D, Saudi Ara- 
bia Cases were gathered between the year of 2009 to 2019 .

The sample size was determined by the total number of mucocele cases presenting to a single surgeon Dr. AAM during his practice, no exceptional conditions were faced.

Nasal endoscopy was carried out for all patients preoperatively and in all post-operative clinic visits.

Contrasted CT of nose and paranasal sinuses was ordered for all patients with navigation protocol MRI was done for some of the complicated cases as indicated Surgical procedures included endoscopic sinus surgery drainage and marsupialization for uncomplicated paranasal sinus mucoceles $(n=15)$ and Modified Endoscopic Lothrop procedures (MELP) for complicated frontal sinus mucoceles $(n=8)$.

Patient hospital charts were reviewed for age, sex, significant presenting symptoms if any, associated significant history, the location and the extension of the mucocele, and previous sinonasal/cranial procedures.

Data were recorded on an $\mathrm{Excel}^{\circledR}$ spreadsheet and descriptive statistics were carried out.

The efficacy was determined by the absence of clinical and radiological recurrence in the total number of patients. The study was approved by the institutional review board of KFSH-D.

\section{Result}

Total of 23 cases were included in this retrospective study, of them, 16 were males and 7 females, age ranging between $14-76$ years, with a mean age of 45 years.

Table 1 elaborates the location of paranasal sinuses mucoceles among the enrolled patients (See Table 1).

12 out of the 23 patients had an intraorbital/intracranial extension, data elaborating the relation of the location of mucoceles and their extensions are reported in (See Table 2).

16 out of the 23 patients had an identified associated risk factor for the development of the mucocele/s (See Table 3).

Table 1. Location of paranasal sinuses mucoceles among the enrolled patients.

\begin{tabular}{cc}
\hline Location & No. of patients (\%) \\
Frontal & $7(30 \%)$ \\
Fronto-ethmoidal & $6(26 \%)$ \\
Ethmoidal & $3(13 \%)$ \\
Sphenoidal & $4(17 \%)$ \\
Maxillary & $3(13 \%)$
\end{tabular}


Table 2. Location of the mucocele and the associated extension if present.

\begin{tabular}{ccc}
\hline & Orbital extension & Intracranial extension \\
\hline Frontal & 3 out of 7 cases & 1 out of 7 cases \\
Fronto-ethmoid & 5 out of 6 cases & 0 \\
Ethmoid & 2 out of 3 cases & 0 \\
Sphenoid & 0 & * cavernous sinus thrombosis \\
Maxillary & 0 & 0 \\
\hline
\end{tabular}

Table 3. Prevalence of risk factors associated with mucocele formation among the total number of patients.

\begin{tabular}{cc}
\hline Risk Factors & No. of patients (\%) \\
\hline Chronic rhinosinusitis & $5(21)$ \\
Facial trauma & $2(8)$ \\
Sinus surgery & $6(26)$ \\
Cranial surgery & $1(4)$ \\
Sinonasal tumor & $1(4)$ \\
\hline
\end{tabular}

One of the patients operated for fronto-ethmoidal mucoceles had an orbital extension into his only seeing eye after losing his right eye in a road traffic accident years before presentation, the mucocele was completely marsupialized endoscopically, saving his vision, the patient has a regular follow up in the clinic with no recurrence (See Figure 1, Figure 2).

Another patient came with a history of a previous open sinus surgery, he presented with left maxillary mucocele after a previous Caldwel-Luc procedure on the same sinus (See Figure 3).

One of the cases of frontal mucoceles presented with a left large frontal extending intracranially, interestingly the patient had no neurological signs or symptoms, he was having an associated chronic pan-sinusitis (See Figure 4), Another patient with bilateral frontal mucocele presented only with Headache (See Figure 5).

Two cases of the patients with history of sinusitis had Allergic fungal sinusitis both presented with an advanced picture of orbital extension, sinuses were marsupialized endoscopically with no need of open approach (See Figure 6, Figure 7).

All of the enrolled 23 cases underwent endonasal endoscopic complete marsupialization, none of them required combination with external approach in-spite of different locations and complications, with no recurrence in a mean follow up period of 2.4 years, Recurrence was defined as visualization of a mucocele on nasal endoscopy, computed tomography (CT) scan, or magnetic resonance imaging (MRI). 

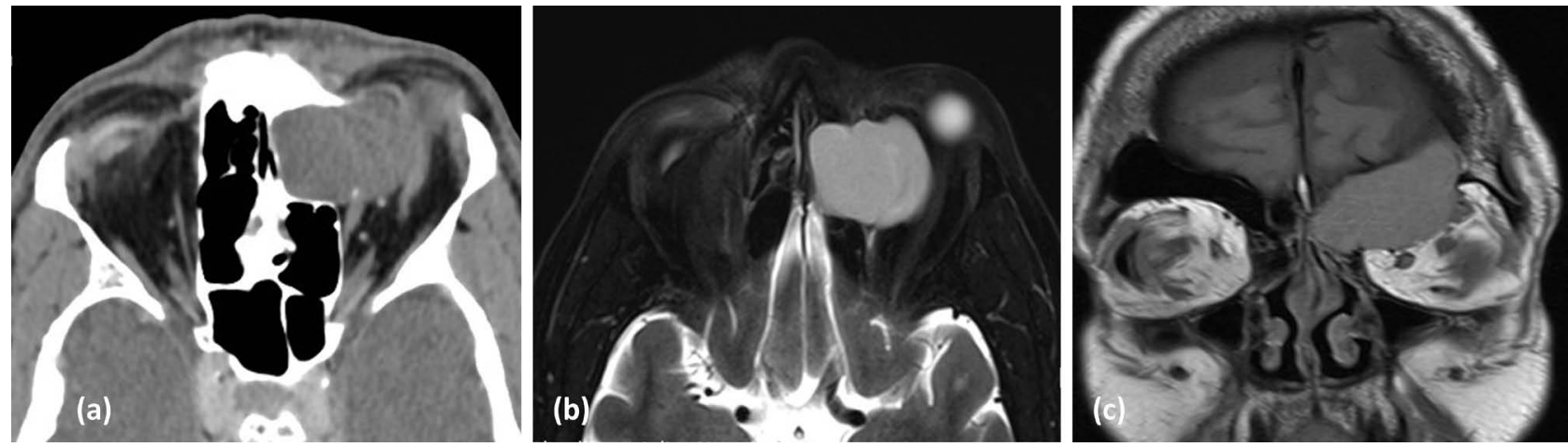

Figure 1. An (a) axial view CT scan showing a left frontoethmoidal mucocele causing bony distruction of the left medial orbital wall, and (b) an axial view MRI (c) coronal view MRI of the same patient presenting with a left fronto-ethmoidal mucocele extending into the left only seeing eye causing mild proptosis, the clinical presentation of the patient was mild proptosis with no vision complaints.

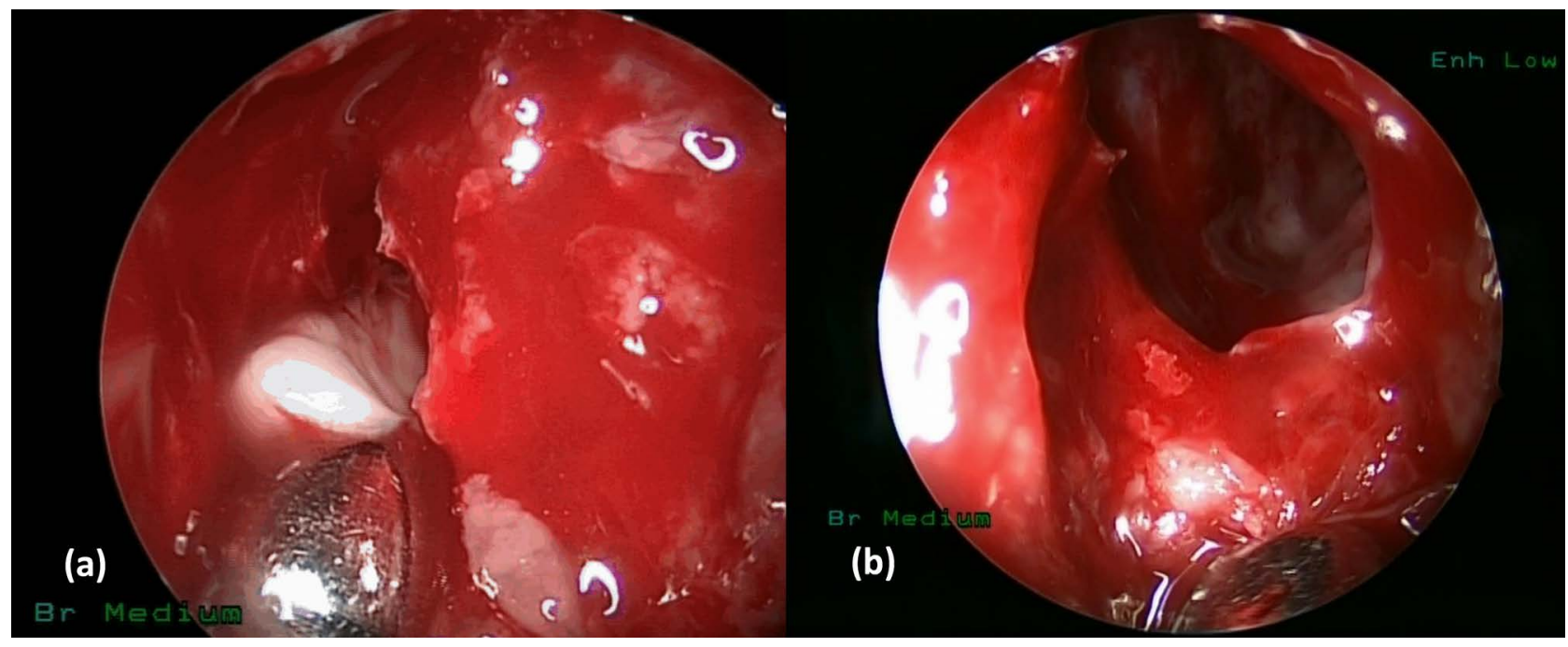

Figure 2. An intraoperative endoscopic view (a) during marsupialization and drainage, (b) after marsupialization of the same previous patient for the left fronto-ethmoidal mucocele showing complete marsupialization.
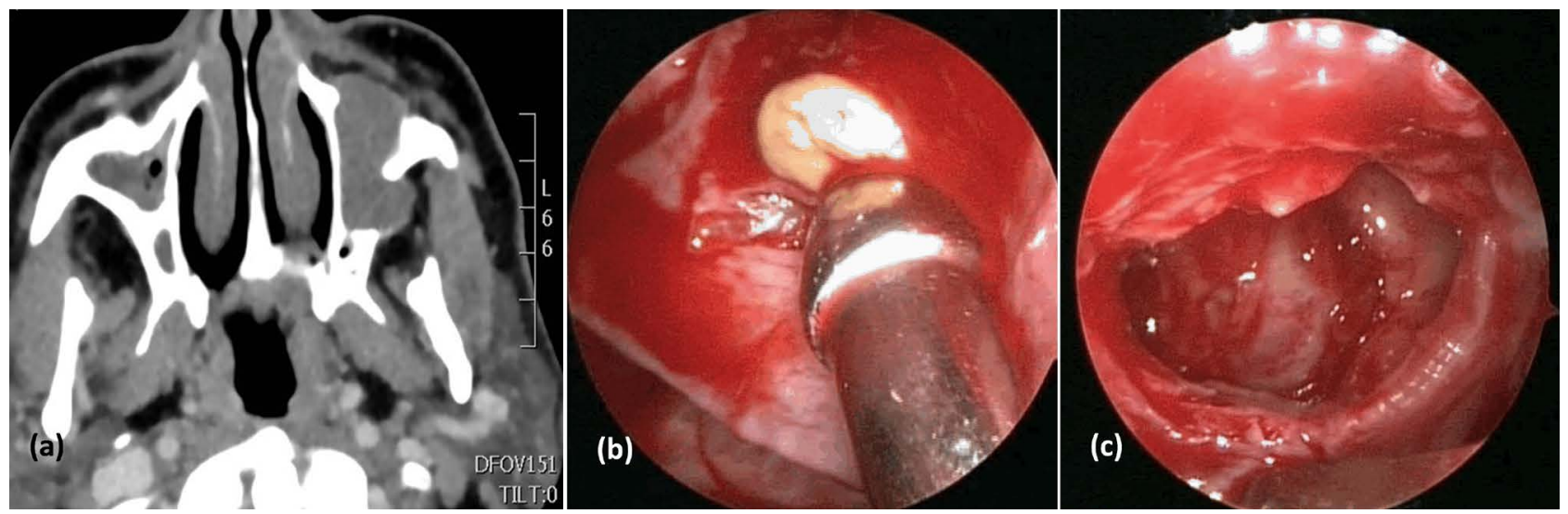

Figure 3. 62 y/o male patient with a previous Caldwel-Luc procedure to the left maxillary sinus presenting with a left check swelling, (a) anterior maxillary wall was removed in the previous surgery and in the postero-lateral aspect the mucocele has eroded the wall into the masticator space, (b) endoscopic view during the marsupialization of the mucocele, (c) the maxillary sinus widely drained post marsupialization. 


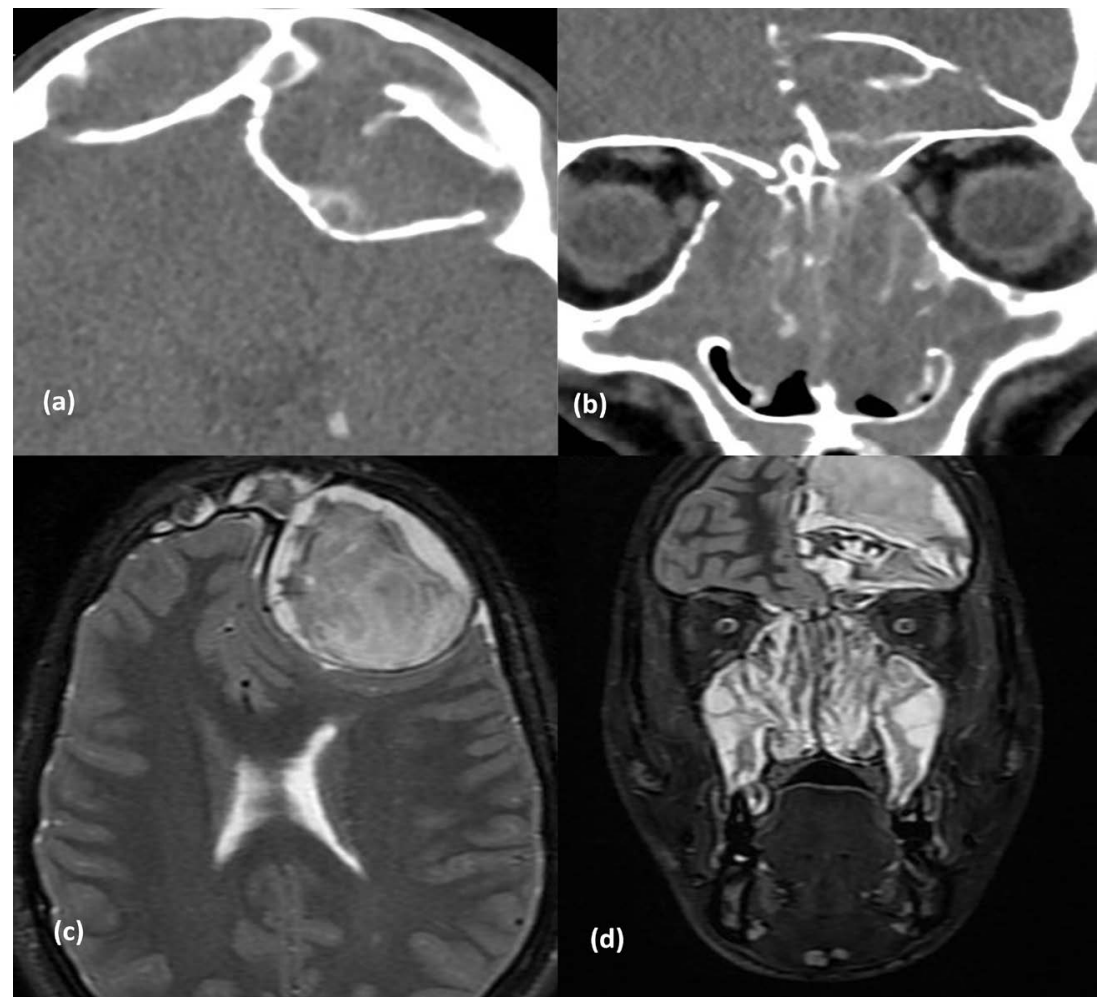

Figure 4. An axial CT (a) and a coronal CT; (b) of a left frontal mucocele with intracranial extension and distruction of the posterior frontal sinus wall in a $17 \mathrm{y} / \mathrm{o}$ male patient presenting with pansinusitis as a complaint, axial MRI; (c) and coronal MRI; (d) of the same patient showing intracranial extradural extension with no orbital extension.

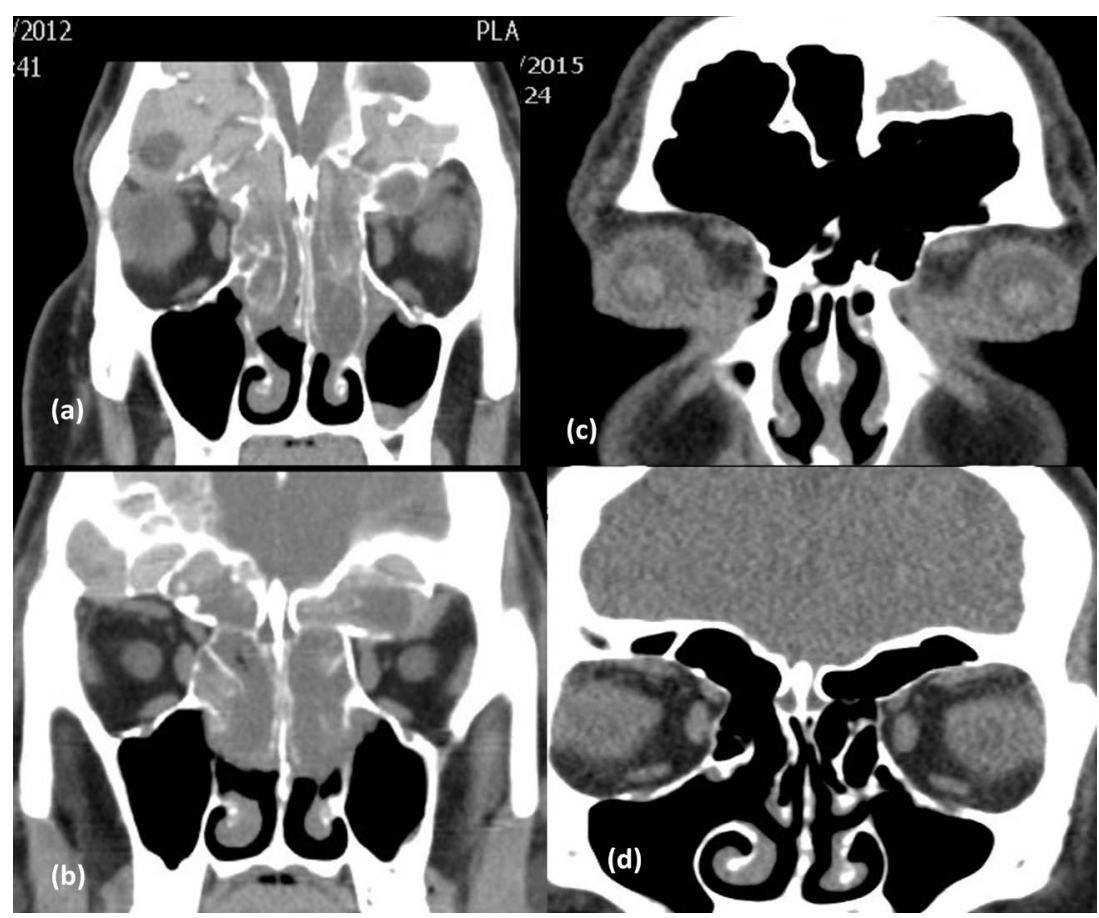

Figure 5. (a), (b) A coronal CT of a 23 y/o male patient presenting with bilateral frontal mucocele with bilateral destruction of the superior orbital wall with intraorbital extraconal extension without orbital symptomatology, the only presenting complaint was headache; (c), (d) Coronal CT of the same patient 3 years post endoscopic marsupialization with no recurrence or new onset symptoms. 


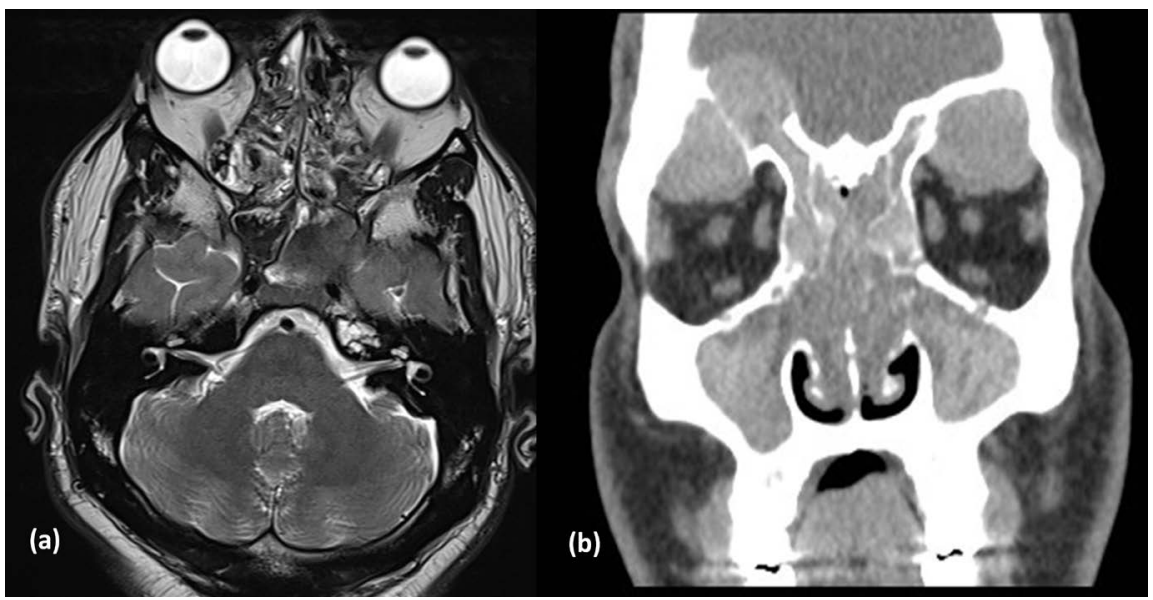

Figure 6. (a) An axial MRI showing bilateral intraorbital mucocele in a 35 y/o male known case of Allergic fungal sinusitis presenting with bilateral frontoethmoidal mucocele with bilateral orbital extension and bilateral proptosis; (b) A coronal CT of the same patient showing the bilateral complete opacification of maxillary, ethmoid and frontal sinuses with bilateral mucocele extension + noting at this cut the thinning of right superior orbital wall and right superior frontal wall, this patient was followed up for 2 years with no recurrence post endoscopic marsupialization.

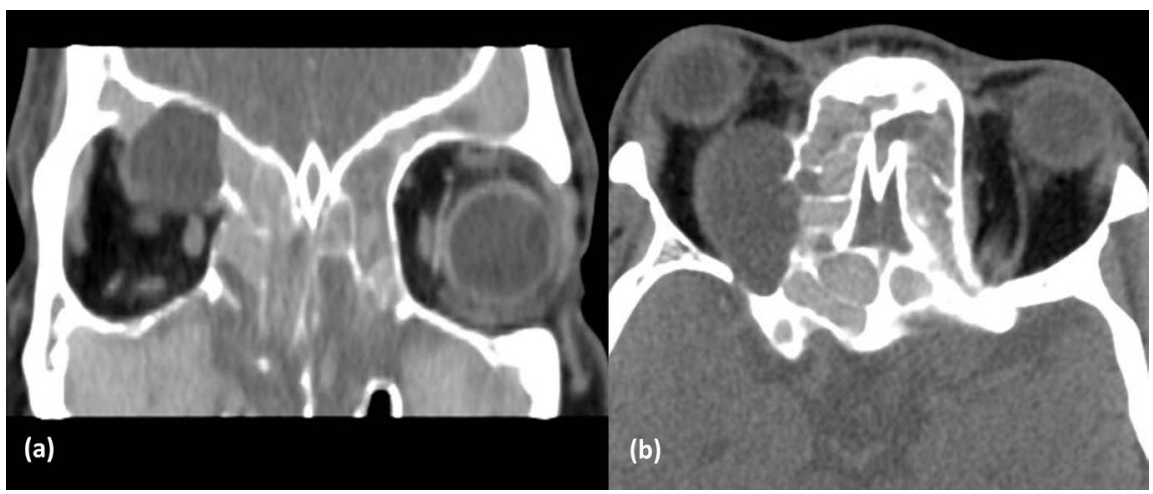

Figure 7. (a) Coronal CT; (b) An axial CT of a 33 y/o male known case of recurrent Allergic fungal sinusitis presenting with right fronto-ethmoidal mucocele with orbital extension compressing on the optic nerve violating the skull base presenting with proptosis, endoscopic marsupialization in 2015 with no recurrence.

\section{Discussion}

In comparison of Endoscopic vs. external approach efficacy and safety, a meta-analysis was published in 2013 by Courson et al. concluded that there was no reported significant difference in the efficacy or recurrence rate between endoscopic vs. open techniques in the treatment of frontal and fronto-ethmoid mucoceles. In fact, Endoscopic technique tended to have lower major complication rates (CSF leak, life threatening infection or blood loss, or loss of vision). Additionally, the external approach was significantly more morbid with respect to minor complications including "post-operative epistaxis requiring packing, temporary vision changes, abnormal scarring, non-life-threatening infections, and sensory nerve damage". 
Recommending also that endoscopic approach should be preferentially offered, while carefully evaluating the patients that might need open approach reserving it for limited indications.

Disclosing that deliberate use of the external approaches may indicate "lack of access to instrumentation, image guidance, and technical familiarity" [21].

Some authors indicated open surgery as a first line treatment in patients with difficult or distorted anatomy, such as case of under developed sinus, a narrow anterior-posterior diameter of the frontal recess, a highly compartmentalized frontal sinus, a large, septated frontal sinus or with mucoceles that are situated within the lateral aspect of the frontal sinus [22].

Although all the reviewed studies [14]-[20] in addition to our study show successful results with recurrence rates at or close to $0 \%$. Nevertheless, it should be emphasized that long term follow-up time is necessary for mucoceles. Thus, the results of these studies, including ours, may not be final.

\section{Conclusion}

Although almost half of our patients presented with orbital and/or intracranial extension, endonasal endoscopic management is a safe, effective approach to treat paranasal sinus mucoceles with different locations and presentations, with a low recurrence rate, and adopting this approach in the treatment of paranasal sinuses mucoceles should be encouraged.

\section{Conflicts of Interest}

The authors declare no conflicts of interest regarding the publication of this paper.

\section{References}

[1] Lund, V. and Milroy, C. (1991) Fronto-Ethmoidal Mucocoeles: A Histopathological Analysis. The Journal of Laryngology \& Otology, 105, 921-923. https://doi.org/10.1017/S0022215100117827

[2] Batsakis, J. (1984) Tumors of the Head and Neck. Williams \& Wilkins, Baltimore.

[3] Paparella, M. (1963) Mucosal Cyst of the Maxillary Sinus. Archives of Otolaryngology, 77, 96. https://doi.org/10.1001/archotol.77.6.96

[4] Fenton, W., Donald, P. and Carlton, W. (1990) The Pressure Exerted by Mucoceles in the Frontal Sinus: An Experimental Study in the Cat. Archives of Otolaryngology: Head and Neck Surgery, 116, 836-840. https://doi.org/10.1001/archotol.1990.01870070084015

[5] Lund, V., Harvey, W., Meghji, S. and Harris, M. (1988) Prostaglandin Synthesis in the Pathogenesis of Fronto-Ethmoidal Mucoceles. Acta Oto-Laryngologica, 106, 145-151. https://doi.org/10.3109/00016488809107382

[6] Baley, B., Johnson, J. and Newlands, S. (2006) Head \& Neck Surgery-Otolaryngology. 4th Edition, Lippincott Williams \& Wilkins, Philadelphia.

[7] Lloyd, G., Lund, V., Savy, L. and Howard, D. (2000) Optimum Imaging for Mucoceles. The Journal of Laryngology \& Otology, 114, 233-236.

https://doi.org/10.1258/0022215001905238 
[8] Har-El, G. (2001) Endoscopic Management of 108 Sinus Mucoceles. The Laryngoscope, 111, 2131-2134. https://doi.org/10.1097/00005537-200112000-00009

[9] Lalwani, A. (2008) Current Diagnosis \& Treatment in Otolaryngology-Head \& Neck Surgery. 2nd Edition, The McGraw-Hill Companies, Inc., New York.

[10] Kennedy, D., Josephson, J., Zinreich, S., Mattox, D. and Goldsmith, M. (1989) Endoscopic Sinus Surgery for Mucoceles. The Laryngoscope, 99, 885-895. https://doi.org/10.1288/00005537-198909000-00002

[11] Khong, J., Malhotra, R., Selva, D. and Wormald, P. (2004) Efficacy of Endoscopic Sinus Surgery for Paranasal Sinus Mucocele Including Modified Endoscopic Lothrop Procedure for Frontal Sinus Mucocele. The Journal of Laryngology \& Otology, 118, 352-356. https://doi.org/10.1258/002221504323086534

[12] Metson, R. (2003) Image-Guided Sinus Surgery: Lessons Learned from the First 1000 Cases. Otolaryngology_Head and Neck Surgery, 128, 8-13. https://doi.org/10.1067/mhn.2003.40

[13] American Academy of Otolaryngology-Head and Neck Surgery (2020) Position Statement: Intra-Operative Use of Computer Aided Surgery [Internet]. https://www.entnet.org/content/intra-operative-use-computer-aided-surgery

[14] Chiu, A. and Vaughan, W. (2004) Management of the Lateral Frontal Sinus Lesion and the Supraorbital Cell Mucocele. American Journal of Rhinology, 18, 83-86. https://doi.org/10.1177/194589240401800203

[15] Bockmuhl, U., Kratzsch, B., Benda, K. and Draf, W. (2006) Surgery for Paranasal Sinus Mucocoeles: Efficacy of Endonasal Micro-Endoscopic Management and Long-Term Results of 185 Patients. Rhinology, 44, 62-67.

[16] Woodworth, B., Harvey, R., Neal, J., Plamer, J. and Schlosser, R. (2008) Endoscopic Management of Frontal Sinus Mucoeceles with Anterior Table Erosion. Rhinology, 46, 231-237.

[17] Sautter, N., Citardi, M., Perry, J. and Batra, P. (2008) Paranasal Sinus Mucoceles with Skull-Base and/or Orbital Erosion: Is the Endoscopic Approach Sufficient? Otolaryngology_Head and Neck Surgery, 139, 570-574. https://doi.org/10.1016/j.otohns.2008.07.004

[18] Bozza, F., Nisii, A., Parziale, G., Sherkat, S., Del Deo, V. and Rizzo, A. (2010) Transnasal Endoscopic Management of Frontal Sinus Mucopyocele with Orbital and Frontal Lobe Displacement as Minimally Invasive Surgery. Journal of Neurosurgical Sciences, 54, 1-5.

[19] Dhepnorrarat, R., Subramaniam, S. and Sethi, D. (2012) Endoscopic Surgery for Fronto-Ethmoidal Mucoceles: A 15-Year Experience. Otolaryngology-Head and Neck Surgery, 147, 345-350. https://doi.org/10.1177/0194599812441570

[20] Casale, M., Costantino, A., Sabatino, L., Cassano, M., Moffa, A. and Rinaldi, V. (2019) Image-Guided Endoscopic Marsupialization Technique for Frontal Sinus Mucocele with Orbital Extension: A Case Report. International Journal of Surgery Case Reports, 61, 259-262. https://doi.org/10.1016/j.ijscr.2019.07.069

[21] Courson, A., Stankiewicz, J. and Lal, D. (2014) Contemporary Management of Frontal Sinus Mucoceles: A Meta-Analysis. The Laryngoscope, 124, 378-386. https://doi.org/10.1002/lary.24309

[22] Kristin, J., Betz, C., Stelter, K., Berghaus, A. and Leunig, A. (2008) Frontal Sinus Obliteration-A Successful Treatment Option in Patients with Endoscopically Inaccessible Frontal Mucoceles. Rhinology, 46, 70-74. 